\title{
In vivo therapeutic effects of albendazole in combination with IFN- $\alpha$ on cystic echinococcosis in mice
}

\author{
Zhelin Yun*1, Yongsheng Zhou ${ }^{1}$, Yan Zhang ${ }^{2}$, Bing $\mathrm{Li}^{1}$ \\ ${ }^{1}$ Department of General Surgery, Baogang Hospital, Baotou, Inner Mongolia, China \\ ${ }^{2}$ The Sci-technology Center, Ningxia Medical University, Yinchuan, Ningxia, China
}

Received: August 30, 2018

Accepted: October 18, 2018

Online Published: December 10, 2018

DOI: $10.14725 /$ dcc.v5n4p9

URL: http://dx.doi.org/10.14725/dcc.v5n4p9

\begin{abstract}
Objective: This study was aimed to evaluate the in vivo therapeutic effects of the combination of ABZ with interferon (IFN)- $\alpha$ on cystic echinococcosis (CE) in mice.

Methods: After 5-month secondary infection with protoscolices, Balb/c mice were randomly divided into four groups: ABZtreated group, IFN- $\alpha$-treated group, ABZ+IFN- $\alpha$ group and untreated control group. Drugs in different treated groups were respectively administered for 2 months. Blood was respectively taken from caudal veins in mice at treatment time points of $0 \mathrm{~d}, 7 \mathrm{~d}, 14 \mathrm{~d}, 28 \mathrm{~d}, 36 \mathrm{~d}, 48 \mathrm{~d}$ and $60 \mathrm{~d}$, in order to detect the changes in the level of antibodies in the serum. Mice were then sacrificed after the end of treatment, and related indicators were detected to evaluate the therapeutic effects.

Results: In comparison with untreated control group $(p<.01)$ and ABZ-treated group $(p<.05)$, ABZ+IFN- $\alpha$ group showed a more significant decrease in the number of cysts, cyst size and cyst weight. After transmission electron microscopy (TEM) of the cysts in different treated groups, it was found that, there was an obvious change in cyst ultrastructure in ABZ+IFN- $\alpha$ group. ELISA experimental results showed that, in ABZ+IFN- $\alpha$ group, there was a significant decrease in IL-10 in serums and splenocytes $(p<.01)$; In comparison with untreated control group, ABZ+IFN- $\alpha$ group showed a more significant decrease in the levels of $\operatorname{IgE}, \operatorname{IgG}$ and its subtypes $(p<.01)$.

Conclusions: In this study, the combination of ABZ with IFN- $\alpha$ was proved to be an effective CE treatment option.
\end{abstract}

Key Words: Cystic echinococcosis, Albendazole, IFN- $\alpha$, IL-10, Ultrastructural modification

Cystic echinococcosis (CE) is a worm-like zoonosis that is widely spread throughout the world and even highly prevalent in some regions. ${ }^{[1]}$ China is one of the countries with the highest incidence of echinococcosis. ${ }^{[2]}$ The treatment of CE usually depends on surgery and/or chemotherapy, and the option hinges on a variety of factors such as the size and location of the cyst, accompanying microbial in- fections, potentially dangerous complications (e.g. cyst rupture, etc. $)^{[3-6]}$ As a supplement to surgical treatment, the only available drug for CE is benzimidazole carbamate derivatives, namely mebendazole (MBZ) and albendazole (ABZ) ${ }^{[7]}$ However, more than $20 \%$ of CE cases responded poorly to the treatment. ${ }^{[8]}$ Therefore, there is an urgent need for some novel and more effective treatment options.

\footnotetext{
*Correspondence: Zhelin Yun; E-mail: Yunzhelin727@126.com; Address: Department of General Surgery, Baogang Hospital, Baotou, Inner Mongolia, China.
} 
Interferon (IFN)- $\alpha$, a type of Grade 1 interferons, was originally used mainly for antiviral treatment of various viral diseases. ${ }^{[9]}$ Subsequently, IFN- $\alpha$ was confirmed to have a variety of biological functions, including: antiviral function, anti-tumor function and immune regulation etc. ${ }^{[9,10]}$ For another type of echinococcosis, i.e., alveolar echinococcosis (AE), some studies have shown that IFN- $\alpha$ has positive protective effects. Godot $\mathrm{V}$ et al. have confirmed that IFN- $\alpha$ can significantly reduce the cysts in patients with AE. ${ }^{[11]}$ It has been further found in the studies that IFN- $\alpha$ can reverse Th2-type responses to Th1-type responses during the treatment of $\mathrm{AE}$, and it is beneficial for body immunity to provoke an effective protective immune response to the cysts. In the study concerning $\mathrm{AE}$, it was also found that IFN- $\alpha$ can relieve the degree of liver fibrosis and injury. However, currently, there is a lack of researches about the therapeutic effect of IFN- $\alpha$ on CE. This study was designed to evaluate the in-vivo therapeutic effect of IFN- $\alpha$ and ABZ-IFN- $\alpha$ on $\mathrm{CE}$ in mice.

\section{Materials and methods}

\subsection{Materials}

\subsubsection{Experimental animals}

All animal experiments were approved by the Ethics Committee in Baogang Hospital in Inner Mongolia. Forty Balb/c female mice (8 weeks old, 18-20 g) were purchased from Beijing Vital River Laboratory Animal Technology Co., Ltd. The experimental animals were raised in a controlled environment at room temperature $\left(22^{\circ} \mathrm{C} \pm 1^{\circ} \mathrm{C}\right)$ under a certain lighting condition (12 h light/dark cycle).

\subsubsection{Drugs and reagents}

ABZ was purchased from GSK, and Pegasys ${ }^{\circledR}$ interferon alfa-2a was purchased from Roche. Penicillin, streptomycin, RPMI 1640 cell culture medium and fetal bovine serum (FBS) were all purchased from Invitrogen. Con-A was purchased from Sigma-Aldrich. ELISA assay kits for mouse IL-4, IL-10 and IFN- $\gamma$ cytokines were purchased from e-Bioscience. Goat Anti-Mouse $\operatorname{IgE}, \operatorname{IgG}$ antibodies and its subtypes of the second antibody were purchased from Novagen. Other reagents were of domestic analytical purity.

\subsubsection{Protoscolices}

After the cysts were isolated with the help of clinical surgery, they were quickly and aseptically transferred to the laboratory. The cystic fluid was extracted from the cysts by use of a syringe, with the weight of $9,000 \times \mathrm{g}$, and centrifuged at $4^{\circ} \mathrm{C}$ for $20 \mathrm{~min}$, with the supernatant discarded.
The settled protoscolices were washed twice by use of PBS containing double antibody $(\mathrm{pH} 7.2$, containing 1,000 $\mu \mathrm{g} / \mathrm{ml}$ penicillin and $1,000 \mathrm{U} / \mathrm{ml}$ streptomyces). The activity of protoscolices was identified with the help of Meilan exclusion experiment. ${ }^{[12]}$ Only when the activity of protoscolices reaches $90 \%$ or more will it be used for subsequent secondary infection in mice. The final concentration of protoscolices used for secondary infection was 1,500/200 $\mu \mathrm{l}$ PBS.

\subsection{Experimental methods}

\subsubsection{Experimental design}

$40 \mathrm{Balb} / \mathrm{c}$ female mice got secondary infection by means of intraperitoneal injection, each mouse was infected with 1,500 fresh protoscolices resuspended in $200 \mu \mathrm{l}$ of PBS. In 5 months after infection, these mice were randomly divided into four groups (10 mice/group): (1) ABZ-treated group, in which mice were given ABZ $(5 \mathrm{mg} / \mathrm{kg})$ by gavage; (2) IFN- $\alpha$-treated group, in which mice were given intramuscular injection of IFN- $\alpha-2 \mathrm{a}(10,000 \mathrm{IU} / 50 \mu \mathrm{l})$ every 3 $\mathrm{d}$; (3) ABZ+IFN- $\alpha$-treated group, in which mice were given ABZ and IFN- $\alpha$, with the same dosage as in (1) and (2); (4) Untreated control group. The drug administration in each group was maintained for 2 months. Subsequently, the mice were sacrificed, and related indicators were detected to evaluate the therapeutic effect.

\subsubsection{Detection of parasitic infection and analysis of ef- fective rate of treatment}

The abdominal cavity of each mouse was dissected to measure the number of cysts, cyst size and cyst weight. Effective rate of treatment (based on cyst weight of the infected mouse) was calculated by the following formula: ${ }^{[13]}$

Effective rate $=(X c-X t) / X c \times 100 \%$

Whereas, $X c$ is the average cyst weight of untreated control group, and $X t$ is the average cyst weight of each treated group.

\subsubsection{Transmission electron microscopy (TEM)}

After each group of cyst samples were processed, they were detected by use of TEM. ${ }^{[14]}$ The cysts were cut into blocks the size of $1 \mathrm{~mm}^{3}$, and fixed with the pre-cooling $0.1 \mathrm{M}$ PBS (containing $2.5 \%$ glutaric dialdehyde) for $5 \mathrm{~h}$. These samples were washed twice with $0.1 \mathrm{M} \mathrm{PBS}$, and fixed with $1 \%$ osmium (VIII) oxide. The samples were then dehydrated in an ascending series of ethanol concentrations and embedded overnight in an equal volume of propylene oxide/epoxy resin. Subsequently, it was again embedded in $100 \%$ fresh epoxy resin for $24 \mathrm{~h}$ and at $65^{\circ} \mathrm{C}$ for $18 \mathrm{~h}$. Ultramicrotome 
(Leica EM FC7) was used to prepare sections with the thickness of 50-70 nm. Afterwards, these sections were placed on 200-mesh copper sieve, and got immersed in saturated uranium acetate and lead citrate staining solutions for $10 \mathrm{~min}$ and $5 \mathrm{~min}$ respectively. The sections were washed with distilled water and dried naturally. TEM (H7650, Hitachi) was applied to the measurement.

\subsubsection{Enzyme linked immunosorbent assay (ELISA)}

First of all, splenocytes isolated from each mouse were resuspended by use of RPMI 1640 medium (containing 10\% heat-inactived FBS), with the final concentration adjusted to $5 \times 10^{6}$ splenocytes $/ \mathrm{ml}$, added by $2.5 \mu \mathrm{g} / \mathrm{ml}$ Con-A (Sigma) stimulants. Under the condition of $37^{\circ} \mathrm{C}$ and $5 \% \mathrm{CO}_{2}$, these cells were incubated for $72 \mathrm{~h}$, followed by the collection of culture supernatant to detect the concentrations of IL-4, IL-10 and IFN- $\gamma$. Specific procedures for the detection of cytokines in serum and cell culture supernatant are described in the instructions of EILSA Cytokine Assay Kit.

ELISA was used to detect the level of antibodies in the serum: 96-well microplate was used in this experiment, 100 $\mu \mathrm{l}$ of $0.1 \mathrm{M}$ phosphate buffer ( $\mathrm{pH} 9.6$, containing $0.1 \mu \mathrm{g} / \mu \mathrm{l}$ cyst crude antigen) was added into each well to be incubated overnight at $4^{\circ} \mathrm{C}$. The serums were diluted into PBST buffer ( $\mathrm{pH} 7.2$, with PBS containing $0.05 \%$ tween-20) under the ratio of $1: 100$, and incubated at $37^{\circ} \mathrm{C}$ for $1 \mathrm{~h}$. Subsequently, the second antibody, i.e., HRP-marked Goat AntiMouse $\operatorname{IgG}, \operatorname{IgG}$ subtype and $\operatorname{IgE}$ under the ratio of 1:1,000, was added. OD value of A490 nm was measured by the enzyme-labeled instrument (Bio-Rad).

\subsection{Statistical analysis}

All data were processed by Prism 5.0 (GraphPad Software) for analysis. The results were represented by mean \pm standard deviation. Cyst weight, size, the concentration of cytokines and the level of antibodies were analyzed by oneway ANOVA respectively. The difference $p<.05$ was considered to be statistically significant.

\section{Results}

\section{1 $\mathrm{ABZ}+\mathrm{IFN}-\alpha$ can significantly suppress the cysts}

All the mice were not dead during the course of the experiment, indicating that there were no serious side effects of drugs. When these mice were sacrificed, the difference in the average weight among 4 groups of mice was of no statistical significance $(p>.05)$. The number of the cysts was obviously lower in ABZ+IFN- $\alpha$-treated group than untreated control group $(p<.01)$ or ABZ-treated group $(p<.05)$; in comparison with untreated control group, the number of the cysts was obviously decreased in ABZ-treated group $(p<.01)$. However, there was no significant difference in the number of the cysts between IFN- $\alpha$-treated group and untreated control group ( $p>.05$, see Table 1$)$.

The results showed that, not only cyst weight but also cyst size was obviously decreased in ABZ+IFN- $\alpha$-treated group in comparison with untreated control group $(p<.01)$ and ABZ-treated group $(p<.05)$; in ABZ+IFN- $\alpha$-treated group, the inhibition rate of the cysts reached $89.7 \%$. It was indicated that the combination of ABZ and IFN- $\alpha$ had a more significant therapeutic effect (see Table 2).

Table 1: The number of the cysts in untreated control group and different treated groups

\begin{tabular}{llllllllllll}
\hline Group & \multicolumn{1}{c}{} & \multicolumn{1}{c}{ The number of the cysts in each mouse } & \multicolumn{2}{c}{ Mean \pm SEM } \\
\hline ABZ group & 3 & 2 & 2 & 1 & 4 & 1 & 2 & 1 & 3 & 2 & $2.100 \pm 0.314$ \\
IFN- $\alpha$ group & 4 & 7 & 3 & 4 & 5 & 1 & 6 & 2 & 4 & 2 & $3.800 \pm 0.592$ \\
ABZ+IFN- $\alpha$ group & 1 & 1 & 1 & 0 & 2 & 1 & 1 & 2 & 0 & 0 & $0.900 \pm 0.233^{* \#}$ \\
Untreated control group & 5 & 4 & 0 & 6 & 2 & 3 & 3 & 5 & 7 & 4 & $3.900 \pm 0.640$ \\
\hline
\end{tabular}

Note. The number of the cysts was more significantly decreased in ABZ+IFN- $\alpha$-treated group than untreated control group $\left({ }^{*} p<.01\right)$ and ABZ-treated group $\left({ }^{\#} p<.05\right)$

Table 2: Cyst weight and size in different groups

\begin{tabular}{llll}
\hline Group & Cyst weight $(\mathbf{g})$ & Cyst size $(\mathbf{m m})$ & Inhibition rate of the cysts $(\%)$ \\
\hline ABZ group & $0.21 \pm 0.17^{*}$ & $2.1 \pm 0.9^{*}$ & 78.4 \\
IFN- $\alpha$ group & $0.89 \pm 0.28$ & $6.7 \pm 1.5$ & 0.08 \\
ABZ+IFN- $\alpha$ group & $0.10 \pm 0.05^{* \#}$ & $1.2 \pm 0.4^{* \#}$ & 89.7 \\
Untreated control group & $0.97 \pm 0.45$ & $7.3 \pm 3.2$ & - \\
\hline
\end{tabular}

Note. Cyst weight and cyst size was more significantly decreased in ABZ+IFN- $\alpha$-treated group than untreated control group $\left({ }^{*} p<.01\right)$ and ABZ-treated group $\left({ }^{\#} p<.05\right)$ 


\subsection{Ultrastructural modification and damages of the cysts in ABZ+IFN- $\alpha$-treated group}

TEM was used to observe ultrastructural modification of the cysts in different groups. The results indicated that the cysts in untreated control group showed a typical cystic structure of echinococcus granulosus, while ABZ+IFN- $\alpha$-treated group showed ultrastructural modification and damages (see Figure $1 \mathrm{~A}$ and $1 \mathrm{~B}$ ). In the germinal layer, normal undifferentiated cells, fibrous tissues, typical nuclei and nucleolus structures in the cysts of mice in $\mathrm{ABZ}+\mathrm{IFN}-\alpha$-treated group disappeared, and karyorrhexis and a large number of lipid droplets appeared instead. As was shown in Figure 1C and $1 \mathrm{D}$, it indicated that the ability of the germinal layer to produce daughter cysts had been damaged. In comparison with untreated control group, the typical cortex and microtrichia microtubule structures of the mouse cysts disappeared in ABZ+IFN- $\alpha$-treated group (see Figure $1 \mathrm{E}$ and $1 \mathrm{~F}$ ). The non-cellular, sugar-rich corneum of the normal outer layer was replaced by an irregular and vacuole-rich structure (see Figure $1 \mathrm{G}$ and $1 \mathrm{H}$ ).
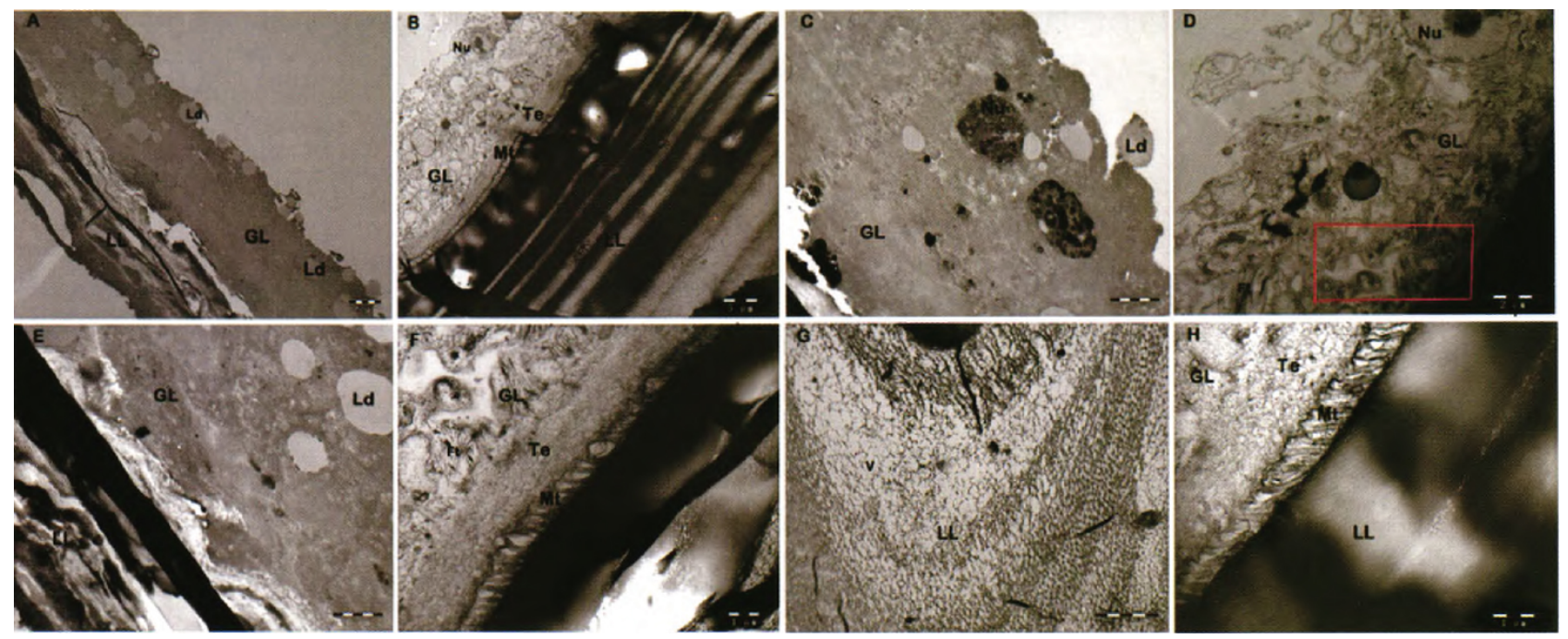

Figure 1: Ultrastructural modification of the cysts in $\mathrm{ABZ}+\mathrm{IFN}-\alpha$-treated group

ABZ+IFN- $\alpha$ treated group (A, C, E and G) and untreated control group (B, D, F and H). A and B showed the general ultrastructure of the cysts; $C$ and $D$ showed the germinal layer of cysts; $E$ and $F$ emphasized on the changes of teguments and microtriches; $\mathrm{F}$ was derived from red rectangle area of $\mathrm{D} ; \mathrm{G}$ and $\mathrm{H}$ represented the laminated layer of cysts. In untreated control group, the cyst has normal laminated layer (LL), germinal layer (GL), tegument (Te), microtriches (Mr), undifferentiated cells (UC), fibrous tissue (F), cell nucleus (Nu) and nucleolus (Nl). In ABZ+IFN- $\alpha$ treated group, ultrastructural modification shows as lipid droplets (Ld) and vaeuloles (V)

\subsection{ABZ+IFN $-\alpha$ treatment can significantly reduce the level of IL-10 in the serum}

To detect the formation of cytokines after treatment, it was found through the detection that the level of IL-10 in the serum was obviously decreased in ABZ+IFN- $\alpha$-treated group than untreated control group $(2.29 \pm 0.25 \mathrm{ng} / \mathrm{ml}$ vs. $3.44 \pm 0.14 \mathrm{ng} / \mathrm{ml}, p<.01$ ) (see Figure $2 \mathrm{~A}$ ). There was no significant difference in the levels of IFN- $\gamma$ (see Figure 2B, $p=.08$ ) and IL-4 (see Figure $2 \mathrm{C}, p=.11$ ) among different groups.

\section{4 $\mathrm{ABZ}+\mathrm{IFN}-\alpha$ treatment can significantly reduce the level of IL-10 secreted by splenocytes}

After detection of the ability of splenocytes to secrete cytokines, it was found that the level of IL-10 was obviously decreased in $\mathrm{ABZ}+\mathrm{IFN}-\alpha$-treated group than untreated con- trol group $(0.91 \pm 0.10 \mathrm{ng} / \mathrm{ml}$ vs. $1.99 \pm 0.17 \mathrm{ng} / \mathrm{ml}, p<$ .01) (see Figure 3A). However, there was no significant difference in the levels of IFN- $\gamma$ (see Figure $3 \mathrm{~B}, p=.31$ ) and IL-4 (see Figure 3C, $p=.18$ ).

\subsection{The changes of specific antibodies in the serum in $\mathrm{ABZ}+\mathrm{IFN}$ - $\alpha$-treated group}

In order to better understand the effect of this treatment option on the level of specific antibodies, ELISA was performed to detect the levels of serum antibodies in different groups. The results showed that, in comparison with untreated control group, the level of IgG antibody was being decreased in ABZ+ IFN- $\alpha$-treated group, and obviously decreased at the end of the treatment (on 60 $\left.{ }^{\text {th }} \mathrm{d}\right)(p<.0001$, see Figure 4A). In addition, at the end of the treatment, the levels of the subtypes of IgG antibody, including IgG1 $(p<$ .0001 , see Figure 4B), IgG2 ( $p=.0299$, see Figure 4C) and 
IgG4 ( $p<.0001$, see Figure 4D) had been significantly decreased as the treatment progressed. Meanwhile, the level of
IgE was also significantly decreased in $\mathrm{ABZ}+\mathrm{IFN}-\alpha$-treated group $(p<.0001$, see Figure 4E).
A

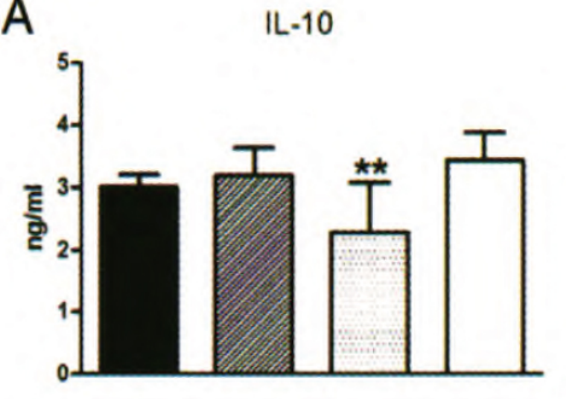

C

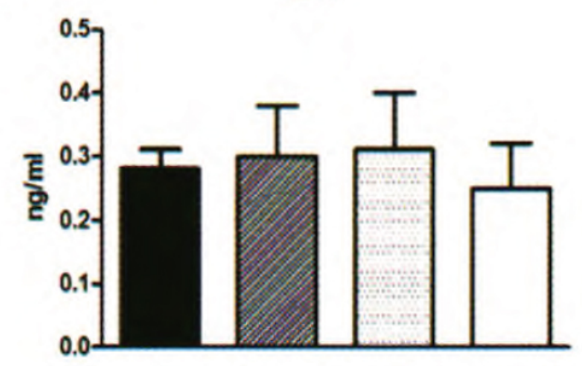

B

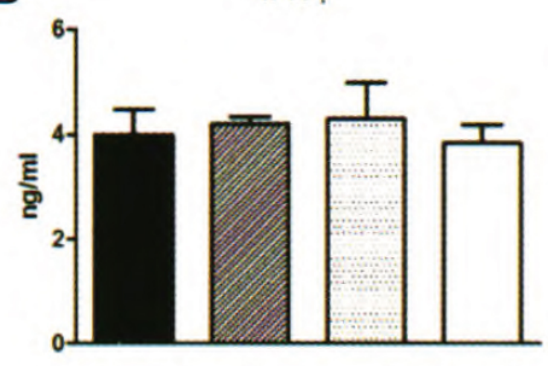

Figure 2: Significant decrease of IL-10 in the serum in ABZ+IFN- $\alpha$-treated group ELISA assay kit was used to detect the concentrations of IL-10 (A), IFN- $\gamma$ (B) and IL-4 (C) in the mouse serums in different groups; ${ }^{* *} p<.01$

A

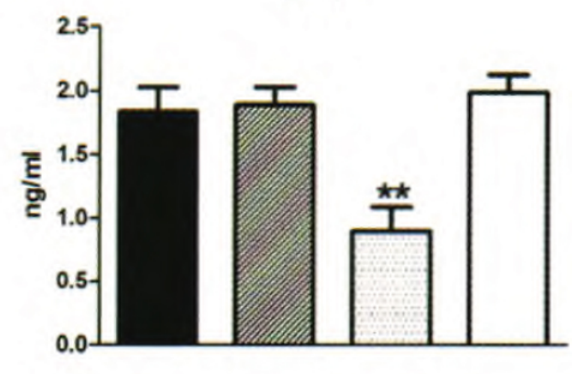

C

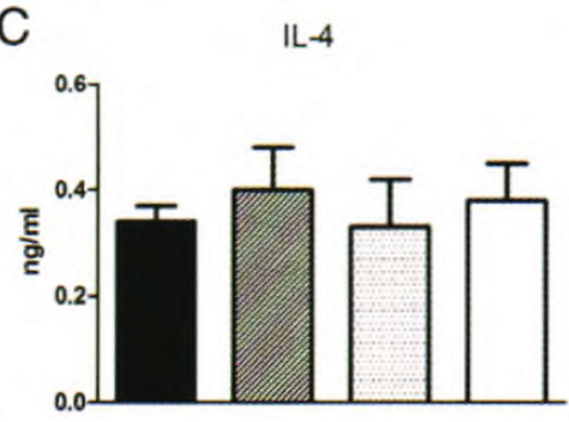

B

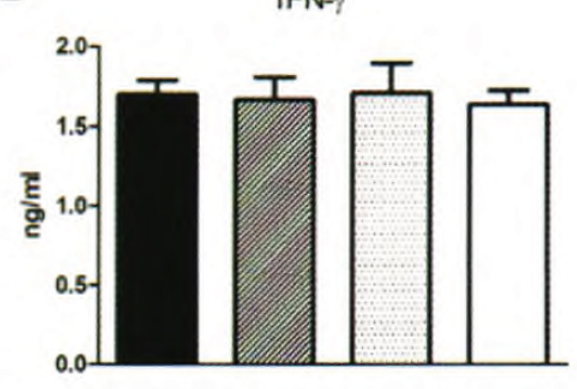

Figure 3: Significant decrease of IL-10 secreted by splenocytes in ABZ+IFN- $\alpha$-treated group ELISA kit was used to detect the concentrations of IL-10 (A), IFN- $\gamma$ (B) and IL-4 (C) in the supernatant of mouse splenocytes in different groups; ${ }^{* *} p<.01$ 
A

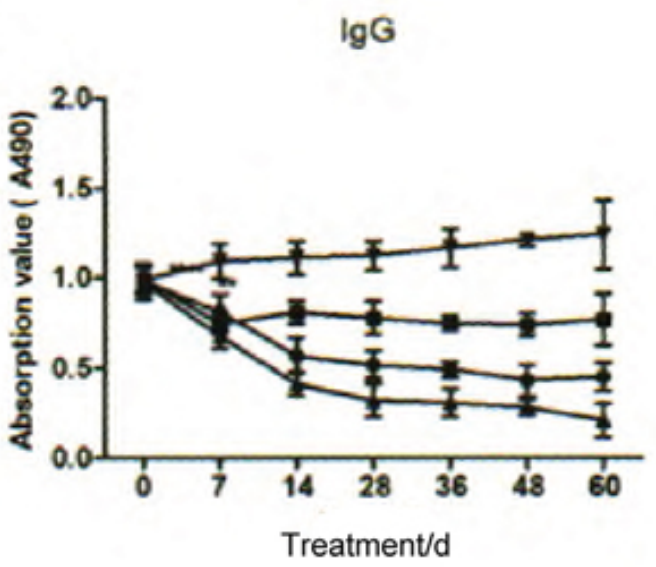

C

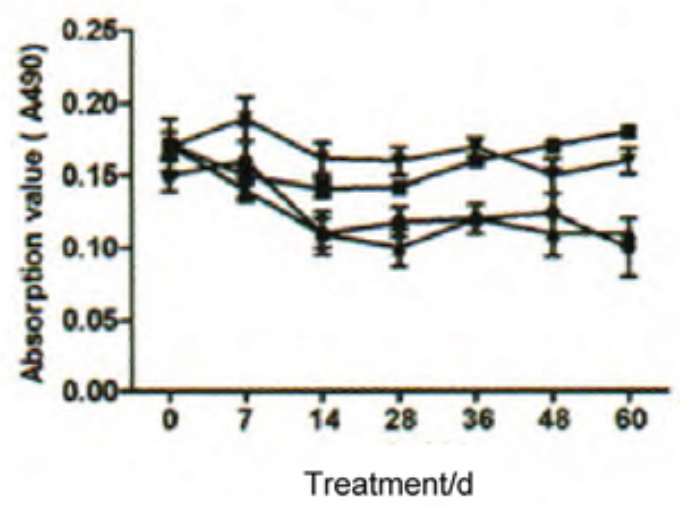

E

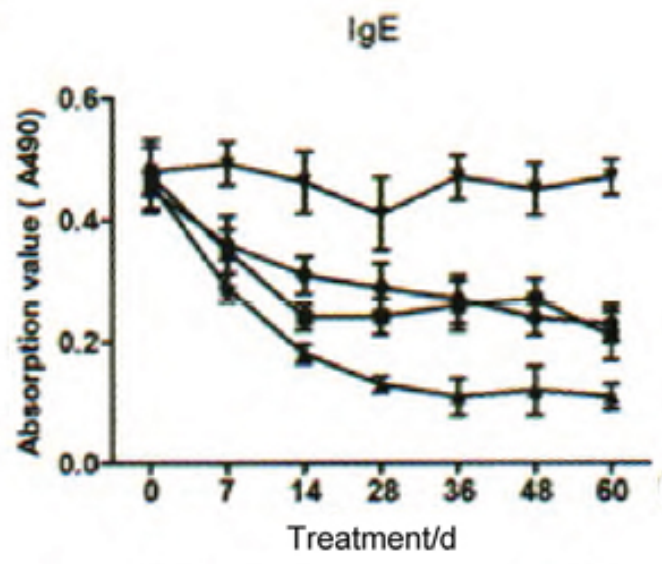

Figure 4: The detection of $\mathrm{IgG}, \operatorname{IgG} 1, \mathrm{IgG} 2, \mathrm{IgG} 4$ and $\operatorname{IgE}$

\section{Discussion}

The therapeutic effect of $\mathrm{ABZ}$ in combination with IFN- $\alpha$ on CE was evaluated in this study. The results showed that ABZ combined with IFN- $\alpha$ had a better therapeutic effect on mice with secondary infection of CE. It was further confirmed that the therapeutic effect may be related to ultrastructural modification of the cysts, decreased IL-10 level and lowered humoral immunity.
B

$\lg G 1$

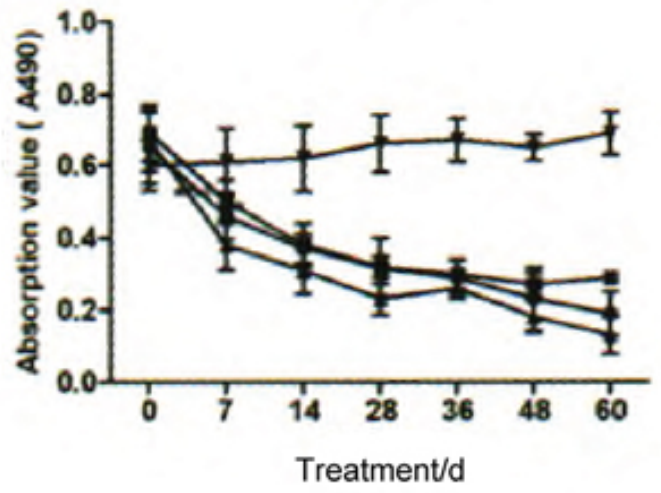

D

$\lg G 4$

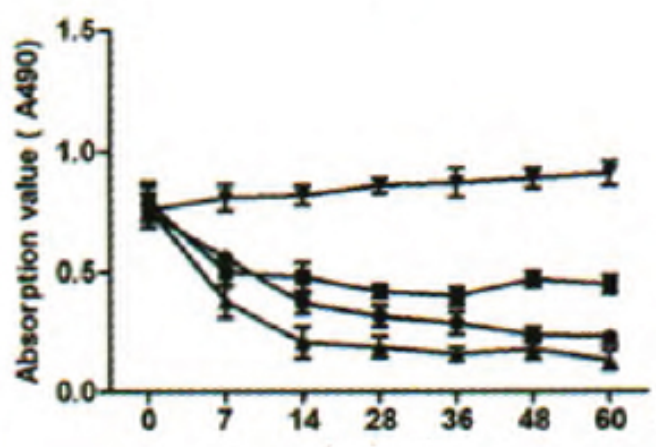

Treatment/d

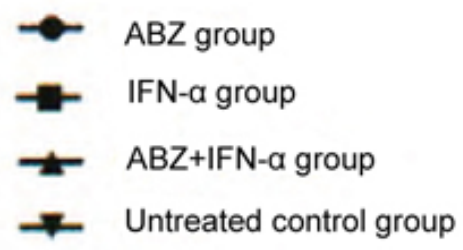

IFN- $\alpha$ has a variety of biological functions including antiviral infection, anti-tumor and immune regulation, but the research on the role in helminthic infection is very limited in its amount. However, it is worth mentioning that in the study of AE, IFN- $\alpha$ can relieve cystic lesions in humans and mice. ${ }^{[11,15]}$ The researchers further stated that this type of effect could be related to the reverse of Th2-type cytokines to Th1-type cytokines, including the down-regulation of IL10 , IL- 6 and IL-13 and the up-regulation of IFN- $\gamma \cdot{ }^{[11]}$ How- 
ever, this study showed that only IFN- $\alpha$ had no effect on alleviating $\mathrm{CE}$ or reversing the type of Th cytokines, which indicated that only IFN- $\alpha$ could not break the Th2-type immune response of chronic $\mathrm{CE}$. This result was different from previous reports on AE treatment. However, IFN- $\alpha$ combined with $\mathrm{ABZ}$ can significantly relieve $\mathrm{CE}$ to reduce the burden of the cysts. Compared with ABZ-treated group or untreated control group, $\mathrm{ABZ}+\mathrm{IFN}-\alpha$-treated group has a better therapeutic effect (see Tables 1 and 2). Further studies have shown that this combination therapy can significantly down-regulate IL-10. IL-10 is a typical Th2-type cytokine that inhibits the Th1 protective response in CE and helps parasites evade the host immune response. ${ }^{[16]}$ Therefore, the better therapeutic effect of the combination therapy may be related to the inhibition of IL-10 and the reduction of Th2-type immune response.

The humoral immune response plays an important role in the occurrence and development of CE. In the early stage of infection, it develops an important protective immune response through complement activation, opsonization and ADCC. Among the antibodies in the chronic phase of infection, especially the IgG4 type, has an effect in facilitating the escape of parasites. ${ }^{[17,18]}$ IgG, IgG1, IgG2, IgG4 and $\operatorname{IgE}$ were all significantly decreased in the combination therapy of this study, indicating that the abnormal rise of humoral immune response in the chronic phase of infection was significantly down-regulated during the process of the

\section{References}

[1] Brunetti E, Kern P, Vuitton DA. Writing Panel for the WI. Expert consensus for the diagnosis and treatment of cystic and alveolar echinococcosis in humans. Acta Tropica. 2010; 114(1): 1-6. PMid: 19931502. https://doi.org/10.1016/j. actatropica.2009.11.001

[2] Qi YF, Wu WP. Progress on the epidemiology of echinococcosis. Chin J Parasitol Paras Dis. 2013; 31(02): 143-148. (in Chinese)

[3] Kern P. Medical treatment of echinococcosis under the guidance of Good Clinical Practice (GCP/ICH). Parasitol Int. 2006; 55 Suppl: S273-82. PMid: 16338164. https://doi.org/10.1016/ j.parint.2005.11.040

[4] Ceballos L, Elissondo C, Moreno L, et al. Albendazole treatment in cystic echinococcosis: pharmacokinetics and clinical efficacy of two different aqueous formulations. Parasitol Res. 2008; 103(2): 355-362. PMid: 18465143. https://doi.org/10.1007/ s00436-008-0980-x

[5] da Silva AM. Hydatid cyst of the liver-criteria for the selection of appropriate treatment. Acta Tropica. 2003; 85(2): 237-242. https : //doi .org/10.1016/S0001-706X (02)00271-1

[6] Wen H, Tu EGAL AJ, Shao YM, et al. Research achievements and challenges for echinococcosis control. Chin J Parasitol Paras Dis. 2015; 33(06): 466-471. (in Chinese)

[7] Falagas ME, Bliziotis IA. Albendazole for the treatment of human echinococcosis: a review of comparative clinical trials. Am J Medl Sci. 2007; 334(3): 171-179. PMid: 17873530. https : //doi.org/10.1097/MAJ .0b013e31814252f8

[8] Moro P, Schantz PM. Echinococcosis: a review. Int J Infect Dis. 2009; 13(2): 125-133. PMid: 18938096. https://doi.org/10. $1016 /$ j.ijid.2008.03.037

Published by New Century Science Press treatment, with IgG4 also significantly reduced. However, although the level of IgG was significantly reduced after the combination therapy, it was found that the level was still higher than the negative level. This may be related to the immune memory of the infection, but it remains to be further studied. In conclusion, the therapeutic effect of the combination therapy may also be related to the down-regulation of the humoral immunity beneficial to the parasites.

In this study, ABZ+IFN- $\alpha$ or IFN- $\alpha$ alone did not significantly increase the level of IFN- $\gamma$ in the chronic phase of infection. This may be related to the fact that IFN- $\gamma$ often plays an important protective role in the early stage of infection (7-8 d) and then decreases in the chronic phase of infection. ${ }^{[19]}$ The effect of the early treatment of infection on IFN- $\gamma$ will be further investigated. In addition, some studies have reported that IFN- $\alpha$ has an anti-tumor effect by enhancing the antigen presenting function of dendritic cells (DCs), ${ }^{[20,21]}$ but it remains to be further explored that whether DCs play a role in this combination therapy.

In conclusion, this study confirmed that $\mathrm{ABZ}$ combined with IFN- $\alpha$ has a better therapeutic effect on $\mathrm{CE}$ and provides an experimental basis for CE treatment.

\section{Conflicts of Interest Disclosure}

The authors have no conflicts of interest related to this article.

[9] Uze G, Tavernier J. High efficiency targeting of IFN-alpha activity: possible applications in fighting tumors and infections. Cytokine Growth Factor Rev. 2015; 26(2): 179-182. PMid: 25466630. https://doi.org/10.1016/j.cytogfr.2014.10.006

[10] Gibbert K, Schlaak JF, Yang D, et al. IFN- $\alpha$ subtypes: distinct biological activities in antiviral therapy. Br $\mathrm{J}$ Pharmacol. 2013; 168(5): 1048. PMid: 23072338. https://doi.org/10.1111/ bph. 12010

[11] Godot V, Harraga S, Podoprigora G, et al. IFN alpha-2a protects mice against a helminth infection of the liver and modulates immune responses. Gastroenterology. 2003; 124(5): 1441-1450. https: //doi.org/10.1016/S0016-5085(03)00273-7

[12] Elissondo M, Dopchiz M, Ceballos L, et al. In vitro effects of flubendazole on Echinococcus granulosus protoscoleces. Parasitol Res. 2006; 98(4): 317-323. PMid: 16374619. https://doi.org/10. 1007/s00436-005-0026-6

[13] Pensel PE, Ullio Gamboa G, Fabbri J, et al. Cystic echinococcosis therapy: Albendazole-loaded lipid nanocapsules enhance the oral bioavailability and efficacy in experimentally infected mice. Acta Trop. 2015; 152: 185-194. PMid: 26409727. https://doi.org/ 10.1016/j.actatropica.2015.09.016

[14] Ahmadnia S, Moazeni M, Mohammadi-Samani S, et al. In vivo evaluation of the efficacy of albendazole sulfoxide and albendazole sulfoxide loaded solid lipid nanoparticles against hydatid cyst. Exp Parasitol. 2013; 135(2): 314-319. PMid: 23912040. https : //doi.org/10.1016/j.exppara.2013.07.017

[15] Harraga S, Godot V, Bressonhadni S, et al. Clinical efficacy of and switch from $\mathrm{T}$ helper 2 to $\mathrm{T}$ helper 1 cytokine profile after interferon a2a monotherapy for human echinococcosis. Clin Infec Dis. 1999; 29(1): 205-206. PMid: 10433588. https://doi.org/10.1086/ 520157 
[16] Manel A, Chafia TB. Involvement of Treg and alternatively activated macrophages in evasion strategies during hydatidosis. Front in Immunol. 2013; 4(4): 41-7. https ://doi.org/10.3389/conf . fimmu. 2013.02.00425

[17] Rigano R, Profumo E, Di Felice G, et al. In vitro production of cytokines by peripheral blood mononuclear cells from hydatid patients. Clin Exp Immunol. 1995; 99(3): 433-439.

[18] Zhang W, Hao W, Li J, et al. Immunology and immunodiagnosis of cystic echinococcosis: an update. Clin Dev Immunol. 2012(1): 101895. https://doi.org/10.1155/2012/101895
[19] Gessner A, Moskophidis D, Lehmann-Grube F. Enumeration of single IFN-gamma-producing cells in mice during viral and bacterial infection. J Immunol. 1989; 142(4): 1293-1298. PMid: 2492578.

[20] Rizza P, Capone I, Moretti F, et al. IFN- $\alpha$ as a vaccine adjuvant: recent insights into the mechanisms and perspectives for its clinical use. Expert Rev Vaccines. 2011; 10(4): 487-498. PMid: 21506646. https://doi.org/10.1586/erv.11.9

[21] Arico E, Belardelli F. Interferon- $\alpha$ as antiviral and antitumor vaccine adjuvants: mechanisms of action and response signature. J Interferon Cytokine Res. 2012; 32(6): 235-247. PMid: 22490303. https://doi.org/10.1089/jir.2011.0077 